\title{
ESTRATIFICAÇÃO E CARACTERIZAÇÃO AMBIENTAL DA ÁREA DE PRESERVAÇÃO PERMANENTE DO RIO GUANDU/RJ
}

\author{
Samara Salamene², Márcio Rocha Francelino³ ${ }^{3}$ Ricardo Valcarcel ${ }^{3}$, João Luiz Lani ${ }^{4}$ e Mariana Médice
} Firme Sás

\begin{abstract}
RESUMO - O Rio Guandu é a principal fonte de abastecimento de água da região metropolitana do Rio de Janeiro, atendendo a, aproximadamente, nove milhões de pessoas. Este trabalho estratificou e caracterizou ambientalmente a Área de Preservação Permanente (APP) do Rio Guandu (faixa marginal de 100m), através da análise de aerofotos digitais não convencionais, obtidas a partir de uma câmera digital de pequeno formato, adaptada a um helicóptero (as aerofotos foram agrupadas em mosaicos para facilitar as etapas do geoprocessamento). A região correspondente a APP foi estratificada em quatro ambientes com características ecológicas distintas: Ambiente 1 (leito encaixado), Ambiente 2 (várzea fluvial), Ambiente 3 (planície aluvionar) e Ambiente 4 (fluviomarinho). A partir da sobreposição dos mapas de uso da terra, da proximidade da área urbano-industrial e da vegetação nativa, foi gerado um mapa do grau de degradação dos ambientes. Os usos predominantes foram pastagem (38\%) e agricultura (18\%). Os fragmentos florestais totalizaram apenas 11,6\% da APP. Segundo a metodologia utilizada, o Ambiente 4 apresentou 51\% de sua área, com um grau alto a muito alto de degradação, e o Ambiente 3 apresentou melhor estado de conservação em comparação aos demais. Os resultados sugeriram que a predominância das atividades agropecuárias, a proximidade de grandes centros urbanos e a área muito reduzida dos fragmentos florestais na APP do Rio Guandu podem comprometer a qualidade desse manancial.
\end{abstract}

Palavras-chave: Mata ciliar, Uso da terra e Conservação.

\section{ENVIRONMENTAL STRATIFICATION AND CHARACTERIZATION OF PERMANENT PRESERVATION AREA IN GUANDU RIVER, RIO DE JANEIRO STATE, BRAZIL}

\begin{abstract}
The Guandu River is the main water provision source in Rio de Janeiro metropolitan area, assisting a population of about nine million people. This study is an environmental stratification and characterization of the Permanent Preservation Area (PPA) in Guandu River, through non-conventional digital aerial photos obtained from a small digital camera attached to a helicopter. These aerial photos have been grouped in mosaics to make the geoprocessing stages easier. The PPA region has been stratified in four different environments: Environment-1 (river-bed), Environment-2 (fluvial holm), Environment-3 (aluvionar plain), Environment-4 (marine influenced). A map of the degree of degradation of each environment has been obtained from the superposition of land use maps, urban-industrial and natural vegetation maps. Generally, the land is used for agriculture and pasture. The forest fragments represent only 7,4\% of the PPA. Environment-4 shows 51\% of high to very high degradation degree, and Environment-3 shows a better conservation state compared to the others. These results suggest that predominance of agricultural activities, proximity of great urban centers and very reduced forest area in the PPA of Guandu River menace the quality of this important source.
\end{abstract}

Keywords: Riparian forest, Land use and Conservation

\footnotetext{
${ }^{1}$ Recebido em 20.03.2009 e aceito para publicação em 16.12.2010.

${ }^{2}$ Instituto Federal de Educação, Ciência e Tecnologia de São Paulo, Brasil. E-mail: <salamene@yahoo.com.br>.

${ }^{3}$ Universidade Federal Rural do Rio de Janeiro, Brasil. E-mail: <marciorocha> e <ricval@ufrrj.br>.

${ }^{4}$ Universidade Federal de Viçosa, Brasil. E-mail: <lani@ufv.br>.

${ }^{5}$ Programa de Pós-Graduação em Solos e Nutrição de Plantas, Universidade Federal de Viçosa, Brasil. E-mail:

<mariana_medice@hotmail.com>.
} 


\section{INTRODUÇÃO}

As matas ciliares, também conhecidas como matas ripárias ou ribeirinhas, são formações florestais que ocupam as margens de cursos de água (AB'SABER, 2004). Esse tipo de vegetação pode apresentar algumas características peculiares, como tolerância a inundações periódicas e capacidade de adaptação em terrenos com alto grau de declividade. São de extrema importância para a manutenção dos ecossistemas aquáticos, pois: auxiliam na infiltração de água no solo, facilitando o abastecimento do lençol freático; mantêm a qualidade da água, dificultando o escoamento superficial de partículas e sedimentos que causam poluição e assoreamento dos recursos hídricos; fornecem sombra, mantendo a estabilidade térmica da água; impedem o impacto direto da chuva no solo, minimizando processos erosivos, e servem de abrigo e alimento para grande parte da fauna aquática (LIMA e ZAKIA, 2004).

Apesar de protegidas por lei federal quando localizadas em Áreas de Proteção Permanente (APPs) (BRASIL, 1965), muitas matas ciliares encontram-se devastadas no Brasil, principalmente devido ao processo de urbanização desordenada e às práticas agrícolas intensivas (MARTINS, 2001). Isso traz, além dos danos ambientais e ecológicos, prejuízos econômicos para o país, uma vez que os recursos hídricos são utilizados no abastecimento de água e na geração de energia elétrica (SALVADOR, 1986).

Em bacias hidrográficas onde existe transposição, as APPs têm papel fundamental na manutenção da qualidade de água, uma vez que, em relação à quantidade desse recurso, o suprimento provém de outras bacias. Esse é o caso do Rio Guandu, no qual grande parte de sua água é proveniente do Rio Paraíba do Sul. Para receber esse volume de água, o Rio Guandu teve, no passado, seu percurso original modificado, sua calha aumentada e seu trecho final retificado para possibilitar uma vazão mais eficiente de suas águas para o oceano (SEMADS, 2001).

Atualmente, o Rio Guandu é a principal fonte de abastecimento da região metropolitana do Rio de Janeiro, atendendo a uma população de cerca de nove milhões de pessoas. Apesar da importância do manancial, esse rio é afetado, atualmente, por graves problemas ambientais devido à poluição oriunda de seus afluentes, às extrações ilegais de areia próximas ao seu curso e à retirada da cobertura vegetal, em razão da ocupação humana e das atividades mineradoras e agropecuárias (ALVES, 2002).
O uso inadequado do solo nas margens de mananciais pode acarretar diminuição significativa da qualidade da água, muitas vezes, dificultando e encarecendo o seu tratamento. Além disso, o histórico de ocupação de uma área originalmente coberta por vegetação ciliar pode determinar sua capacidade e velocidade de regeneração (GASPARINO et al., 2006).

Alguns projetos para recuperação da mata ciliar do Rio Guandu já foram implantados, como o Projeto Muda Guandu, desenvolvido pelo Governo do Estado do Rio de Janeiro em 2002. Porém, muitos desses projetos são executados sem considerar fatores ambientais primordiais como relevo, uso da terra adjacente, tipo de solo, declividade do terreno e riscos de erosão (DURIGAN e NOGUEIRA, 1990). O uso de sensoriamento remoto e de sistemas de informações geográficas (SIGs) pode auxiliar a determinação de alguns desses fatores (FLORENZANO, 2002). Estudos recentes de mapeamento do uso da terra têm utilizado aerofotos digitais não convencionais, principalmente devido ao seu baixo custo em comparação à aquisição de outras imagens de alta resolução (e.g. CUNHA et al., 2006; ENDRES et al., 2006).

Projetos para recuperar matas ciliares são custosos e envolvem riscos, portanto, devem ser bem planejados. O objetivo desse trabalho foi estratificar e caracterizar ambientalmente a Área de Preservação Permanente (100m em ambas as margens) do Rio Guandu/RJ.

\section{MATERIAL E MÉTODOS}

\section{1 Área de estudo}

O Rio Guandu está situado na região da Baixada Fluminense (Figura 1) e possui $48 \mathrm{~km}$ de extensão e largura variável (50 a 90m). Dois terços de sua vazão são oriundos do Rio Paraíba do Sul, através de uma transposição. Para receber esse maior volume de água, o Rio Guandu foi bastante modificado a partir da década de 1950, quando foram realizadas várias obras de dragagem e retificação da sua calha para melhor escoamento das águas para a Baía de Sepetiba (SEMADS, 2001).

O campo de estudo compreendeu a Área de Preservação Permanente do Rio Guandu, estabelecida pelo Código Florestal Brasileiro (BRASIL, 1965), que abrange 100 metros de extensão a partir das margens do Rio. A APP do Rio Guandu situa-se no domínio da Mata Atlântica, numa altitude que varia de 0 a 30m. 


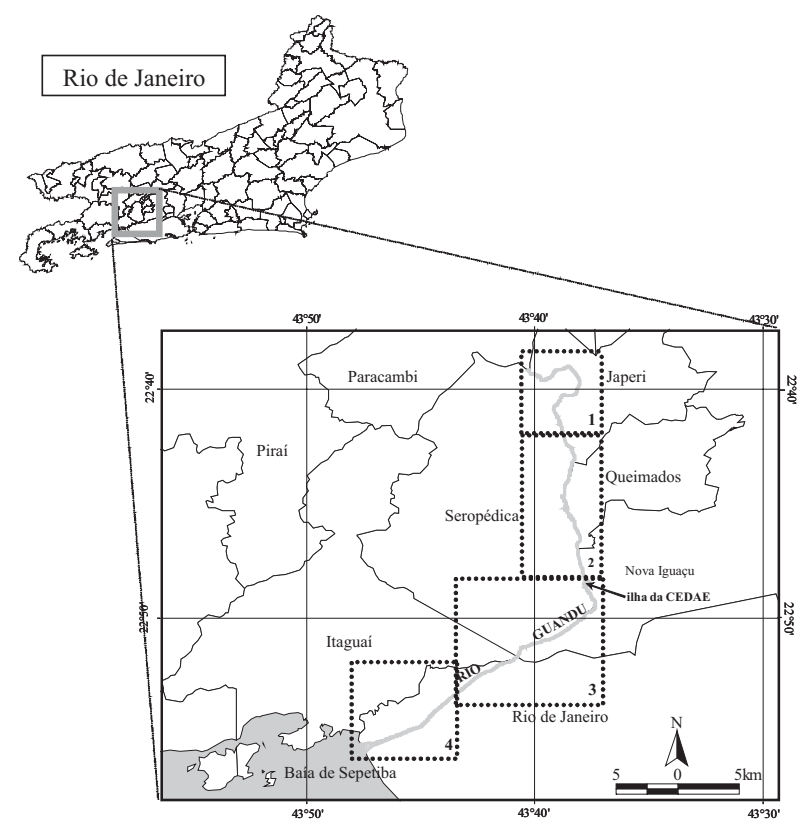

Figura 1 - Localização geográfica do rio Guandu e seus ambientes (1 a 4) no Estado do Rio de Janeiro.

Figure 1-Localization of the Guandu River and its environments (1-4) in Rio de Janeiro State, Brazil.

O clima predominante na área é o Aw de Köppen. O regime pluviométrico é caracterizado pela existência de um período chuvoso, de dezembro a março (verão), e de estiagem, de junho a agosto (inverno). A precipitação média anual é de $1.270 \mathrm{~mm}$, de acordo com dados do período de 1997 a 2006, da estação meteorológica da PESAGRO, em Seropédica/RJ. A umidade relativa média anual é de $80 \%$ e a temperatura média anual varia de 20 a $27^{\circ} \mathrm{C}$, sendo que a média das mínimas está entre 15 e $23^{\circ} \mathrm{C}$ e a média das máximas entre 26 e $32^{\circ} \mathrm{C}$ (SEMADS, 2001).

\subsection{Aerofotos e uso da terra}

Para o mapeamento do uso da terra foram utilizadas 130 aerofotos digitais de pequeno formato, obtidas em 13-6-2006, através de uma câmera modelo F-717 da Sony (5.0 megapixels), disparada automaticamente por um intervalômetro digital. A câmera foi acoplada a um helicóptero do tipo “esquilo”, cujo plano de voo estabeleceu uma sobreposição de $60 \%$ entre as fotos. A altura de voo $(1.000 \mathrm{~m})$ permitiu gerar imagens com escala aproximada de 1:3.000. Cada fotografia cobriu uma área aproximada de $876 \mathrm{~m}$ x 650m, apresentando uma resolução espacial de $30 \mathrm{~cm}$.
As imagens foram agrupadas em mosaicos, utilizando o software no PanaVue 2.10 (PANAVUE, 2002) e o geoprocessamento foi realizado no ArcGis 9.0 (ESRI, 2004). A vetorização do Rio, no formato shapefile, a partir do qual foi gerado um buffer de 100 metros de distância para cada lado do Rio. O mapa de uso da terra foi feito através de fotointerpretação e vetorização, também em formato shapefile, utilizando-se escala de 1:3.000. As coordenadas geográficas do mapa foram transformadas em UTM e Datum (SIRGAS 2004).

Em relação ao uso da terra, foram definidas nove classes: agricultura, capoeira, mangue, mata, pastagem, restinga, solo exposto, urbano-industrial e várzea, cujos perímetros e áreas foram calculados.

A mata compreendeu as florestas em estágio médio a avançado de regeneração e, a capoeira, as florestas em estágios iniciais desse processo. A relação áreaperímetro dos fragmentos florestais foi calculada através da dimensão fractal (D), cuja equação é dada pela área (S) e perímetro (P) do fragmento. Partes simples e regulares terão valor de D próximo a 1 e fragmentos complexos terão, aproximadamente, valor igual a 2 (YAMAJI, 2001).

$$
\mathrm{D}=\frac{\log \mathrm{S}}{\log \mathrm{P}}
$$

\subsection{Estratificação da APP}

A área do leito do Rio Guandu foi estratificada em quatro ambientes (Figura 1): Ambiente 1 - leito encaixado; Ambiente 2 - várzea fluvial; Ambiente 3 - planície aluvionar e Ambiente 4-fluviomarinho (próximo à foz).

Para descrever e delimitar esses diferentes ambientes, foram utilizados os dados da literatura; as observações de campo; as aerofotos digitais; o mapa de uso da terra da APP na escala 1:3.000; os mapas de geomorfologia (GOES, 2005) e os mapas de solos (EMBRAPA, 2001; GOES, 2001), na escala 1:50.000. O relevo também foi considerado um fator determinante para a delimitação dos ambientes, sendo a altitude ao longo do Rio descrita através de um perfil topográfico obtido a partir de um Modelo Digital de Elevação (MDE). O MDE do Rio Guandu foi obtido por meio de uma imagem SRTM (MIRANDA, 2005), reamostrada para resolução de 30 metros no ArcGIS 9.0.

Revista Árvore, Viçosa-MG, v.35, n.2, p.221-231, 2011 
O limite entre os Ambientes 1 e 2 foi definido de acordo com o final do domínio de colinas e o início da área com ocorrência de vegetação de várzea, conforme observado nas aerofotos. Os Ambientes 2 e 3 foram separados pelas duas barragens presentes no Rio, na altura da chamada "ilha da CEDAE”, onde o nível da água é reduzido a 1/3 da vazão após a passagem por essas barragens de captação. O Ambiente 4 apresenta influência marinha pela cunha salina de $8 \mathrm{~km}$ rio adentro, partindo da foz (SEMADS, 2001).

\subsection{Grau de degradação ambiental}

Foi gerado, no ArcGIS 9.0, um mapa com o grau de degradação da APP em cada ambiente do Rio Guandu, com base nos dados de uso da terra, de proximidade da área urbana e de área com vegetação nativa em estágio médio a avançado de regeneração. Para cada categoria, foram atribuídos pesos entre 0 e 1, de acordo com o nível de contribuição para a degradação ambiental, sendo 0 para o menor nível e 1 para áreas com nível máximo de contribuição (Tabela 1). O mapa de uso da terra foi convertido para o formato grid, no qual foram adicionados à sua tabela os pesos para cada classe de uso.
O mapa de proximidade da área com vegetação nativa em estágio médio a avançado de regeneração considerou que essa extensão consiste numa fonte natural de propágulos, fazendo com que as áreas mais próximas sejam mais regeneráveis do que as mais distantes dessa vegetação. Esse mapa foi gerado a partir de um grid dos limites cobertos por mata, mangue e restinga, utilizando-se o algoritmo Distância Euclidiana. Foram atribuídos os pesos de acordo com as distâncias da mata, que, por sua vez, foram estabelecidas segundo RANTA et al. (1998) e PIRES et al. (2004), nas quais a maioria das espécies dispersoras consegue locomoverse por até 350 metros em áreas abertas adjacentes à floresta. O mesmo procedimento foi realizado para obtenção do mapa de proximidade da área urbanoindustrial, considerando que as áreas adjacentes sejam mais impactadas do que as mais afastadas. Zonas num raio superior a 200 metros de distância das áreas urbanoindustriais estariam sendo menos afetadas pelos impactos de natureza antrópica.

Esses três temas gerados foram submetidos à álgebra de mapa, que realizou a soma dos pesos individuais através da ferramenta Map Calculator do ArcGIS. Essa soma serviu de base para a classificação do grau de

Tabela 1 - Pesos atribuídos para cada tema em relação ao grau de degradação na APP do rio Guandu, RJ.

Table 1 - Loads attributed for each theme in relation to degradation degree in APP of the Guandu River, RJ.

\begin{tabular}{|c|c|c|}
\hline Tema & Classe & Peso \\
\hline 1. Uso da terra & $\begin{array}{c}\text { Mata } \\
\text { Mangue } \\
\text { Restinga } \\
\text { Capoeira } \\
\text { Cultivos } \\
\text { Pastagens } \\
\text { Várzea } \\
\text { Solo exposto } \\
\text { Urbano-industrial }\end{array}$ & $\begin{array}{c}0 \\
0 \\
0 \\
0,25 \\
0,50 \\
0,50 \\
0,75 \\
0,75 \\
1\end{array}$ \\
\hline $\begin{array}{l}\text { 2. Proximidade davegetação nativa } \\
\text { (mata, mangue e/ou restinga) }\end{array}$ & $\begin{array}{c}0 \text { a } 50 \text { metros } \\
50 \text { a } 100 \text { metros } \\
100 \text { a } 200 \text { metros } \\
200 \text { a } 350 \text { metros } \\
\text { Maior que } 350 \text { metros }\end{array}$ & $\begin{array}{c}0 \\
0,25 \\
0,50 \\
0,75 \\
1 \\
\end{array}$ \\
\hline 3. Proximidade da área urbano-industrial & $\begin{array}{c}0 \text { a } 50 \text { metros } \\
50 \text { a } 100 \text { metros } \\
100 \text { a } 150 \text { metros } \\
150 \text { a } 200 \text { metros } \\
\text { Maior que } 200 \text { metros }\end{array}$ & $\begin{array}{c}1 \\
0,75 \\
0,50 \\
0,25 \\
0\end{array}$ \\
\hline Grau de degradação(soma dos 3 pesos) & $\begin{array}{c}\text { Baixo } \\
\text { Moderado } \\
\text { Alto } \\
\text { Muito alto } \\
\end{array}$ & $\begin{array}{c}0 \text { a } 0,75 \\
0,75 \text { a } 1,50 \\
1,50 \text { a } 2,25 \\
2,25 \text { a } 3 \\
\end{array}$ \\
\hline
\end{tabular}

Revista Árvore, Viçosa-MG, v.35, n.2, p.221-231, 2011 
degradação da APP nos ambientes do Rio Guandu. Posteriormente, foi realizada uma reclassificação para o cálculo da porcentagem das áreas de acordo com as classes do grau de degradação.

\section{RESULTADOS E DISCUSSÃO}

A vegetação nativa na Área de Preservação Permanente do Rio Guandu representou 13,3\% do total de 934,4ha da APP (Tabela 2). Desse percentual, 11,6\% compreenderam remanescentes florestais, sendo que apenas 7,4\% equivaleram a florestas em estágio médio a avançado de sucessão ecológica (mata), e o restante $(4,2 \%)$ correspondeu a florestas em estágios iniciais de regeneração (capoeira). Esse resultado não difere dos encontrados por outros autores para vegetações ribeirinhas (FERREIRA e DIAS, 2004; GASPARINO et al., 2006). Outros tipos de ecossistemas naturais encontrados nas margens do Rio Guandu foram mangue e restinga, que corresponderam, respectivamente, a $1,2 \%$ e $0,5 \%$ da APP.

Quanto ao uso antrópico da terra (agricultura, pastagem, solo exposto e urbano-industrial), as classes totalizaram $75 \%$ da APP. A pastagem foi o uso mais expressivo, cobrindo 38,3\%. Em outros estudos de levantamento do uso da terra em bacias hidrográficas, a pastagem também foi a classe de uso mais representativa (e.g. CUNHA et al., 2006; NASCIMENTO et al., 2006). O tipo de ocupação do solo pode influenciar a manifestação dos processos erosivos, sendo esses de maior intensidade em áreas mais antropizadas (ENDRES et al., 2006).

A várzea representou 11\% da APP e consistiu em espécies higrófilas invasoras que ocuparam as margens do Rio após o alagamento promovido por barragens e, ou, assoreamento (SEMADS, 2001). Os cursos de água adjacentes - como rios afluentes e lagoas ocuparam $0,7 \%$ da APP.

A mata ciliar encontra-se distribuída em 96 fragmentos, sendo a maioria deles (71) com área menor do que 1 ha. O tamanho dos fragmentos variou de 0,02 a 3,94ha e o tamanho médio geral dessas partes foi igual a $0,72 \mathrm{ha}$, com desvio padrão de $\pm 0,93 \mathrm{ha}$. Apenas três fragmentos apresentaram área maior do que 3ha. O pequeno tamanho dos fragmentos, associado à vizinhança desses com classes de uso de solo resultantes de ações antrópicas, podem indicar que os mesmos vêm sofrendo vários tipos de distúrbios (NASCIMENTO et al., 2006).

A dimensão fractal (D), encontrada na relação área/ perímetro dos fragmentos, variou de 1,3 a 1,5 (D 1), indicando que as partes remanescentes apresentaram, em geral, formas simples, ou seja, menos sinuosas, o que diminui o efeito de borda (YAMAJI, 2001).

O histórico de ocupação do solo da Bacia Hidrográfica do Rio Guandu, primeiramente para uso agrícola e posteriormente para implantação de indústrias diversas, expansão urbana e extração de areia, foram os principais responsáveis por essa redução drástica da vegetação natural. Na região onde se situa essa bacia, predominava originalmente a Mata Atlântica (VELOSO e GÓES-FILHO, 1982), mas com a grande destruição da vegetação nativa, a paisagem foi severamente modificada, havendo, hoje, o predomínio de pastagens e áreas degradadas.

O índice de degradação, calculado com base no uso da terra, na distância da área com vegetação nativa e na extensão urbano-industrial, demonstrou que apenas

Tabela 2 - Uso da terra nos quatro ambientes da APP do rio Guandu, RJ.

Table 2 - Land use in four environments of Permanent Preservation Area on Guandu River, Rio de Janeiro State, Brazil.

\begin{tabular}{|c|c|c|c|c|c|c|c|c|c|c|}
\hline \multirow[t]{2}{*}{ Uso da terra } & \multicolumn{2}{|c|}{ APP } & \multicolumn{2}{|c|}{ Amb.1 } & \multicolumn{2}{|c|}{ Amb.2 } & \multicolumn{2}{|c|}{ Amb.3 } & \multicolumn{2}{|c|}{ Amb.4 } \\
\hline & (ha) & $(\%)$ & (ha) & $(\%)$ & (ha) & $(\%)$ & (ha) & $(\%)$ & (ha) & $(\%)$ \\
\hline Agricultura & 165,6 & 17,7 & 26,0 & 12,0 & 15,3 & 5,9 & 88,2 & 32,4 & 36,1 & $\overline{19,3}$ \\
\hline Capoeira & 39,4 & 4,2 & 5,5 & 2,6 & 8,1 & 3,1 & 20,5 & 7,5 & 5,3 & 2,8 \\
\hline Mangue & 10,9 & 1,2 & - & - & - & - & - & - & 10,9 & 5,8 \\
\hline Mata & 69,1 & 7,4 & 12,2 & 5,6 & 18,8 & 7,3 & 33,9 & 12,5 & 4,1 & 2,2 \\
\hline Pastagem & 357,7 & 38,3 & 108,2 & 50,2 & 81,2 & 31,3 & 85,6 & 31,5 & 82,6 & 44,2 \\
\hline Restinga & 5,0 & 0,5 & - & - & - & - & - & - & 5,0 & 2,6 \\
\hline Solo exposto & 70,0 & 7,5 & 22,8 & 10,6 & 21,9 & 8,4 & 19,6 & 7,2 & 5,7 & 3,0 \\
\hline Urbano-industrial & 107,9 & 11,5 & 34,7 & 16,1 & 14,5 & 5,6 & 21,6 & 7,9 & 37,2 & 19,9 \\
\hline Várzea & 103,0 & 11,0 & 4,7 & 2,2 & 96,1 & 37,0 & 2,2 & 0,8 & - & - \\
\hline
\end{tabular}


26\% da APP do Rio Guandu apresentaram um baixo grau de degradação, tendo grande parte da área apresentado degradação moderada (41\%) e, o restante (33\%), uma degradação alta a muito alta (Tabela 3). A predominância das classes de uso antrópico da terra influenciou no resultado desse índice. Além disso, 43\% da APP encontram-se a até 200m de distância da área urbana e, 30\%, acima de 350m de distância da área coberta por vegetação nativa em estágio médio a avançado de regeneração, o que explica os resultados obtidos pelo índice de degradação.

Apesar da maioria das espécies conseguirem alcançar até 350m em áreas abertas adjacentes às florestas nativas (PIRES et al., 2004), alguns insetos e aves não atravessam distâncias acima de 100m (RANTAet al., 1998). Na Tabela 3 , podemos constatar que 63\% da APP do Rio Guandu consistem em áreas que distam mais de 100m das matas, o que pode dificultar a dispersão de propágulos e, consequentemente, a regeneração dessas áreas.

Abdullah e Nakagoshi (2007) determinaram que a fragmentação das florestas está correlacionada positivamente com os usos antrópicos da terra, como agricultura, pastagens e áreas urbanas. Segundo esses autores, a utilização de um único índice em diferentes paisagens naturais pode ser um caminho para identificar as áreas florestais naturais mais ameaçadas. Concluíram, ainda, que para melhor planejamento e manejo do uso da terra, é vital a compreensão da relação entre os seus diferentes usos antrópicos e o grau de degradação da floresta medido por um único índice.
É preciso ressaltar que existe a possibilidade de outros fatores físicos influenciarem na degradação ambiental, como tipo de solo, relevo e clima, e que os critérios utilizados neste trabalho enfatizaram apenas os fatores relacionados aos diferentes tipos de uso da terra.

Os resultados sugerem que somente a criação de leis e decretos não garante a preservação de matas ciliares. Além de estabelecer uma largura mínima da faixa marginal, com o objetivo de conservar uma floresta ribeirinha, deveriam ser levados em consideração a comunidade vegetal - pois a extensão do efeito de borda varia de acordo com a espécie arbórea - e o uso da terra ao redor da floresta - pois inclusive florestas ribeirinhas largas são vulneráveis à influência de usos da terra circunvizinhos (RODEWALD e BAKERMANS, 2006).

O Rio Guandu apresentou diferentes ambientes ao longo de seu curso. A predominância dos tipos de uso da terra, bem como o número e o tamanho de fragmentos florestais (Figura 2), variaram nos diferentes ambientes e essa distinção foi influenciada, principalmente, pela variação do relevo (Figura 3). A região de confluência do Rio Santana com o Ribeirão das Lages, onde se inicia o Rio Guandu, apresenta uma paisagem bem distinta das que se notam na jusante. Nesse local, devido a um afunilamento natural da calha, o Rio segue encaixado e meandrado. Já nas áreas de baixada, próximas às margens, há presença de áreas alagadas e, em seguida, de solos aluvionares (áreas propícias à extração de areia). No trecho final retificado,

Tabela 3 - Grau de degradação, proximidade da área urbano-industrial e da área com vegetação nativa. Table 3 - Degradation degree, area proximity with native vegetation and urban-industrial.

\begin{tabular}{|c|c|c|c|c|c|c|}
\hline \multirow[t]{2}{*}{ Tema } & \multirow[t]{2}{*}{ Classes } & \multicolumn{5}{|c|}{ Área (\%) } \\
\hline & & $\mathrm{APP}$ & Amb.1 & Amb.2 & Amb.3 & Amb.4 \\
\hline \multirow{5}{*}{$\begin{array}{l}\text { Proximidade da área } \\
\text { urbano-industrial }\end{array}$} & até 50 m & 18 & 23 & 12 & 16 & 25 \\
\hline & 50 a $100 \mathrm{~m}$ & 8 & 8 & 8 & 7 & 7 \\
\hline & 100 a $150 \mathrm{~m}$ & 10 & 11 & 9 & 8 & 12 \\
\hline & 150 a 200 m & 8 & 8 & 8 & 5 & 11 \\
\hline & acima de 200 m & 57 & 50 & 63 & 64 & 46 \\
\hline \multirow{5}{*}{$\begin{array}{l}\text { Proximidade da vegetação } \\
\text { nativa (mata, mangue } \\
\text { e/ou restinga) }\end{array}$} & até $50 \mathrm{~m}$ & 24 & 22 & 26 & 27 & 20 \\
\hline & 50 a $100 \mathrm{~m}$ & 13 & 15 & 15 & 15 & 8 \\
\hline & 100 a $200 \mathrm{~m}$ & 21 & 26 & 24 & 23 & 8 \\
\hline & 200 a 350 m & 12 & 17 & 15 & 10 & 4 \\
\hline & acima de $350 \mathrm{~m}$ & 30 & 21 & 21 & 25 & 61 \\
\hline \multirow[t]{4}{*}{ Grau de degradação } & baixo & 26 & 25 & 23 & 30 & 26 \\
\hline & moderado & 41 & 40 & 44 & 49 & 23 \\
\hline & alto & 22 & 18 & 28 & 15 & 28 \\
\hline & muito alto & 11 & 17 & 5 & 6 & 23 \\
\hline
\end{tabular}

Revista Árvore, Viçosa-MG, v.35, n.2, p.221-231, 2011 


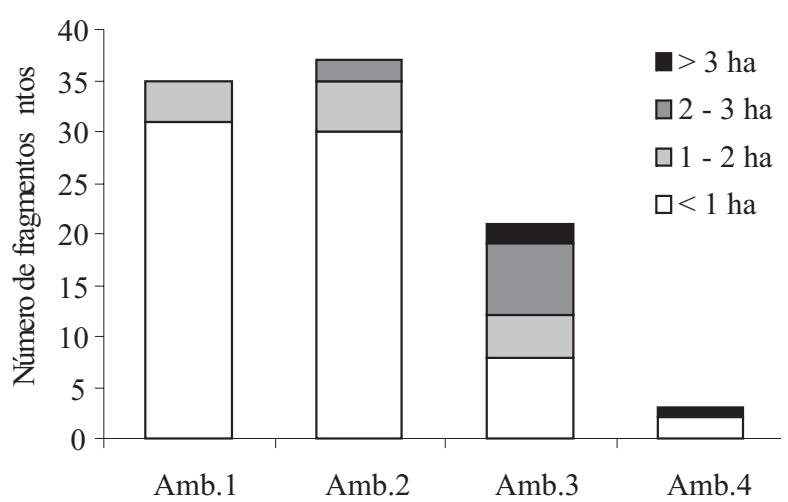

Figura 2 - Número de fragmentos de mata ciliar nos quatro ambientes do rio Guandu, separados em classes de tamanho (ha).

Figure2-Fragments(numbers) of ciliary forest in the four environments on Guandu River, separates in classes size.

denominado Canal de São Francisco, a vegetação ciliar sofre influência marinha, devido à penetração da cunha salina nesse canal.

Nesse contexto, verifica-se a ocorrência de quatro tipos de ambientes ao longo do Rio Guandu (Tabela 4): faixa marginal onde o Rio corre encaixado (Ambiente 1); área extensa de planície com vegetação típica de várzea (Ambiente 2); planícies aluvionares (Ambiente 3) e ambiente fluviomarinho, próximo à foz do Rio (Ambiente 4).

\subsection{Ambiente 1 - Leito encaixado}

No Ambiente 1, o Rio apresenta meandros e a calha encontra-se encaixada entre colinas, fazendo com que boa parte da margem seja delimitada pelo terço inferior das encostas. A altitude aumenta à medida que se afasta da margem do Rio, formando vales estruturais. Esse ambiente está situado numa altitude que varia de 30 a 40m, sendo que, em alguns locais, há presença de colinas que chegam a $100 \mathrm{~m}$.
A APP, nesse ambiente, possui cerca de 220ha e $11 \mathrm{~km}$ de extensão. Geomorfologicamente, predominam colinas estruturais, isoladas e com topos aplainados (GOES, 2005). Quanto aos solos, há presença de Gleissolo, Neossolo, Cambissolo, Argissolo Vermelho-Amarelo e Planossolo (GOES, 2005).

A classe de uso da terra que se destacou foi a pastagem, ocupando 50\% da APP nesse ambiente. A expressiva ocorrência de pastagens e cultivos no Ambiente 1 pode ser explicada pelo grande número de propriedades rurais nessa área. A classe de uso urbano-industrial também teve peso relevante, principalmente devido ao fato desse ambiente abranger parte da área urbana dos municípios de Queimados e Japeri, além de algumas fábricas situadas próximas à margem do Rio Guandu.

A mata ciliar apresenta um elevado número de fragmentos em comparação com os demais ambientes (35), sendo que a maioria desses fragmentos (31) possui área menor do que 1 ha. Esse tamanho reduzido faz com que o efeito de borda abranja praticamente toda a área, podendo, muitas vezes, causar impacto na comunidade vegetal, como o aumento na mortalidade de árvores (NASCIMENTO e LAURANCE, 2006).

Nesse ambiente, 35\% da APP encontram-se em estado alto a muito alto de degradação ambiental. Por se tratar de uma área que apresenta maior declividade próxima às margens do Rio, esse resultado pode indicar uma grande suscetibilidade desse ambiente a processos erosivos.

\subsection{Ambiente 2 - Várzea fluvial}

A APP no Ambiente 2 possui cerca de 13,5km de extensão e está situada numa altitude que varia de 11 a 20m. Quanto à geomorfologia, há, nesse ambiente, colina aplainada, planície aluvionar e várzea fluvial, com predomínio desta última, e, quanto aos solos, predominam Planossolo e Gleissolo (GOES, 2005).

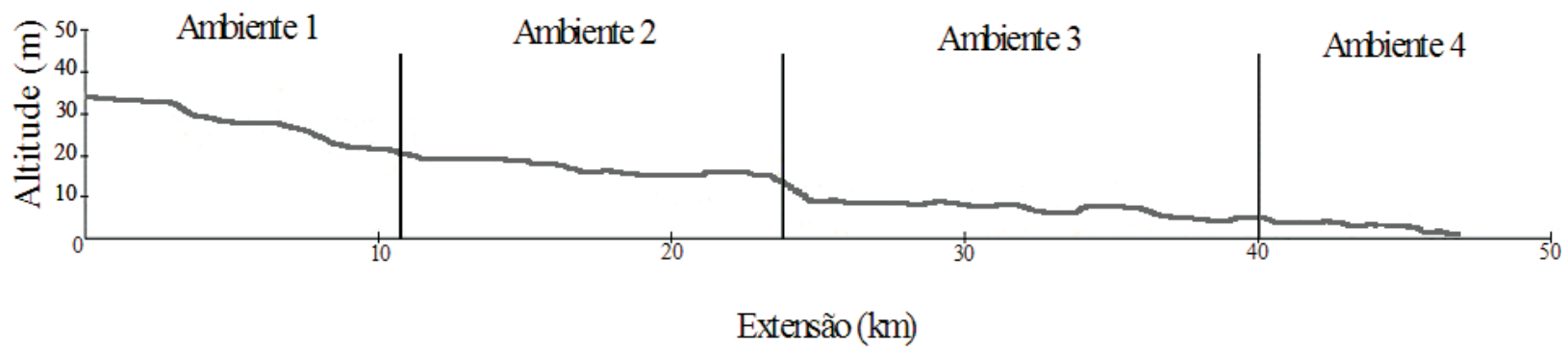

Figura 3 - Perfil topográfico do rio Guandu, com os limites de abrangência dos seus quatro ambientes. Figure 3 - Topographical profile of the Guandu River, with inclusion limits of their four environments. 
Tabela 4 - Principais características de cada ambiente do rio Guandu, RJ.

Table 4 - Main characteristics of each environment on Guandu River, RJ.

\begin{tabular}{|c|c|c|c|c|c|c|c|}
\hline Amb. & Geo. & $\begin{array}{l}\text { Altitude } \\
\quad(\mathrm{m})\end{array}$ & $\begin{array}{l}\text { APP } \\
\text { (ha) }\end{array}$ & $\begin{array}{l}\text { Extensão } \\
(\mathrm{km})\end{array}$ & Solos & $\begin{array}{c}\text { Uso(s) } \\
\text { predominante(s) }\end{array}$ & Frag. \\
\hline 1 & Leito encaixado & $20-30$ & 216 & 11 & $\begin{array}{l}\text { Argissolo, Planosssolo, } \\
\text { Neossolo e Cambissolo }\end{array}$ & Pastagem & 35 \\
\hline 2 & Várzea fluvial & $11-20$ & 260 & 13,5 & $\begin{array}{c}\text { Planossolo, Neossolo e } \\
\text { Gleissolo }\end{array}$ & Várzea & 37 \\
\hline 3 & Aluvionar & $5-12$ & 272 & 16 & Gleiossolo e Planossolo & $\begin{array}{c}\text { Agricultura e } \\
\text { pastagem }\end{array}$ & 21 \\
\hline 4 & Fluvio-marinho & $0-10$ & 187 & 8 & Gleissolo & $\begin{array}{c}\text { Pastagem e } \\
\text { urbano-industrial }\end{array}$ & 3 \\
\hline
\end{tabular}

Nota: Amb. = ambientes; Geo. = geomorfologia; Frag. = número de fragmentos.

Nesse ambiente, as várzeas fluviais ocuparam $37 \%$ do solo da APP do Rio Guandu. A presença significativa de Gleissolo, juntamente com outras variáveis, determina uma paisagem de áreas alagáveis, que por sua vez favorece o desenvolvimento de uma vegetação bem característica, com plantas herbáceas higrófilas, como Typha sp (taboa) e Costus spicatus (Jacq.) Sw. (canavieira-do-brejo), resistentes a inundações. A pequena representatividade das classes de uso urbano-industrial e dos cultivos demonstra a baixa potencialidade dessas áreas para esses fins, devido, principalmente, ao fato dessas extensões estarem sujeitas a alagamentos.

Apesar de possuir mais fragmentos de mata ciliar do que os demais ambientes (37), apenas sete apresentam uma área superior a 1 ha. Segundo SEMADS (2001), a retirada da mata ciliar nativa e a construção das barragens para captação de água no Rio Guandu propiciaram o rápido desenvolvimento das espécies herbáceas higrófilas e invasoras. Essas espécies não conseguem conter os processos erosivos que ocorrem no solo das margens do Rio, gerando uma grande deposição de sedimentos na calha, o que dificulta o tratamento da água.

A presença marcante das várzeas fluviais foi responsável pela maior porcentagem de áreas com moderado e alto grau de degradação. Além disso, 63\% da área encontram-se situados acima de 200m de distância da classe urbano-industrial, o que justifica o fato de apenas 5\% da área ter sido considerada com um grau muito alto de degradação ambiental. Apesar desse ambiente ter apresentado o maior número de fragmentos, $21 \%$ de sua APP ainda se encontram muito distantes das fontes de propágulos.

\subsection{Ambiente 3 - Planície aluvionar}

Na planície aluvionar, a Área de Preservação Permanente possui cerca de $16 \mathrm{~km}$ de extensão, sendo o ambiente de maior área do Rio Guandu. Quanto à geomorfologia, apresenta praticamente planície aluvionar em toda a APP(GOES, 2005). A formação do tipo planície aluvionar é muito utilizada para exploração de areia, sendo tal atividade observada de forma intensa nessa área, próxima ao curso do Rio. Segundo GOES (2005), nesse ambiente, há predomínio de solos aluviais (Neossolos Quartzarênico e Flúvico).

A agricultura foi a classe de uso da terra mais abundante, com 32,4\%, seguido da pastagem, com 31,5\%. Essa região é composta por diversas propriedades rurais que produzem, principalmente, grande quantidade de coco e banana, o que pode explicar os resultados obtidos. Além disso, a presença marcante de solos aluviais que geralmente apresentam acúmulo de matéria orgânica no horizonte A - e o clima quente da região favorecem essas práticas.

Esse ambiente apresentou a maior área de matas ciliares do Rio Guandu, que ocupam $20 \%$ do solo. Os quase 34ha de mata encontram-se espalhados em 21 fragmentos, sendo dois desses com área superior a 3ha. Esses resultados contribuíram para que esse ambiente, até então, mostrasse melhor estado de conservação em comparação com os demais ambientes, com 79\% de sua área considerada como de grau baixo a moderado de degradação ambiental.

Apesar disso, esse ambiente possui 21\% de terras com grau alto e muito alto de degradação e, ainda, 25\% da área não são atingidos pelas fontes de propágulos, o que não dispensa a preocupação com esse ambiente em relação à degradação. Ressalta-se que esse ambiente 
é o de maior extensão no Rio Guandu e existem apenas $20 \%$ da área coberta com vegetação nativa, ou seja, cinco vezes menos do que o previsto na legislação.

\subsection{Ambiente 4 - Fluviomarinho}

O Ambiente 4 é o de menor extensão do Rio Guandu, possuindo 8km até a foz na Baía de Sepetiba. Apresenta uma planície fluviomarinha praticamente em toda a sua extensão, onde existem basicamente solos do tipo Gleissolo (EMBRAPA, 2001).

Nesse ambiente, ocorre a penetração da cunha salina no Canal de São Francisco, influenciando nas formações da paisagem, o que pode ser constatado pela presença de mangues e restingas na área. A cunha salina introduz-se no canal sob a água doce do Rio, devido à maior densidade da água do mar em comparação à fluvial e sua extensão depende diretamente da altura da maré e da vazão do Rio.

O uso da terra predominante foi a pastagem, com 44,2\%, havendo também destaque para a área urbanoindustrial, ocupando quase $20 \%$ da extensão. Isso se explica pelo fato desse ambiente estar inserido no distrito industrial de Santa Cruz, no município do Rio de Janeiro, onde existem grandes empresas. A proximidade desse polo urbano-industrial foi um fator determinante para esse ambiente ser o mais impactado do Rio Guandu, apresentando 51\% de sua área com grau alto a muito alto de degradação.

Além disso, a presença de apenas três fragmentos florestais - com tamanhos muito reduzidos - e a intensa destruição das áreas originalmente cobertas por restingas e manguezais - que ocorre ao longo de toda a costa fluminense - fizeram com que $61 \%$ da APP, nesse ambiente, estivessem muito afastadas da vegetação nativa, prejudicando o processo de regeneração natural nas áreas adjacentes.

\section{CONCLUSÃO}

A Área de Preservação Permanente do Rio Guandu apresentou $11,6 \%$ de sua extensão coberta com diferentes formas florestais, $1,2 \%$ de mangue e $0,5 \%$ de restinga, totalizando apenas 13,3\% de ecossistemas que contribuem para a manutenção da qualidade da água. Os fragmentos florestais encontram-se muito reduzidos quanto ao tamanho de suas áreas, sofrendo grande influência do efeito de borda, o que pode comprometer a sua sustentabilidade ambiental.
O Rio Guandu foi estratificado em quatro ambientes distintos. Cada um apresentou variações na paisagem, mas, em geral, a pastagem foi o uso da terra predominante na APP. Essa estratificação deve ser considerada quando forem implementados projetos para a reabilitação desses ambientes. O ambiente fluviomarinho (4) apresentou um elevado grau de degradação, enquanto o ambiente de planície aluvionar (3) encontra-se em melhor estado de conservação em comparação aos demais ambientes. A proximidade de um polo industrial e o maior tamanho dos fragmentos florestais foram, respectivamente, os fatores que mais influenciaram nos resultados obtidos nos ambientes 4 e 3 .

\section{AGRADECIMENTOS}

Agradecemos: à CAPES (Coordenação de Aperfeiçoamento de Pessoal de Nível Superior), pela bolsa de mestrado concedida à primeira autora; ao Ministério Público e à Polícia Militar do Estado do Rio de Janeiro, representados por Rogério de Lima e Silva Caldas, por, respectivamente, disponibilizarem as aerofotos digitais e concederem helicóptero e pilotos para o sobrevoo no Rio Guandu, e ao Núcleo de Estudos do Planejamento e Uso da Terra (NEPUT), do Departamento de Solos da Universidade Federal de Viçosa (UFV), pela utilização do software ArcGIS 9.0.

\section{REFERÊNCIAS}

AB'SABER, A.N. O suporte geoecológico das florestas beiradeiras (ciliares). In: RODRIGUES, R.R. e LEITÃO-FILHO, H.F. (Ed.). Matas Ciliares: conservação e recuperação. $2^{a}$ ed. São Paulo: Edusp/Fapesp, 2004. 320p.

ABDULLAH, S.A.; NAKAGOSHI, N. Forest fragmentation and its correlation to human land use change in the state of Selangor, peninsular Malaysia. Forest Ecology and Management, Maryland Heights, v.241, p.39-48, 2007.

ALVES, A.G. Ações poluidoras na Bacia do Rio Guandu e suas conseqüências para ETA Guandu. In: SEMINÁRIO BACIA HIDROGRÁFICA DO RIO GUANDU: Problemas e Soluções. Anais... Seropédica: UFRRJ/SERLA, 2002, CD-ROM.

Revista Árvore, Viçosa-MG, v.35, n.2, p.221-231, 2011 
BRASIL. Lei no 4.771 de 15/09/1965.

CUNHA, A.M.; LANI, J.L.; AMARAL, E.F.; REZENDE, S.B.; RIBEIRO, L.S. Mosaico digital de aerofotos não-convencionais na avaliação de recursos naturais: estudo de caso.

Revista Brasileira de Engenharia Agrícola e Ambiental, Campina Grande, v.10, n.1, p.182-187, 2006.

DURIGAN, G.; NOGUEIRA, J.C.B.

Recomposição de Matas Ciliares: orientações básicas. São Paulo: IF/Série Registros, n.4, 1990. 14p.

EMPRESA BRASILEIRA DE PESQUISA AGROPECUÁRIA. Zona Oeste do Município do Rio de Janeiro: Solos. Rio de Janeiro: Embrapa-Solos, 2001.

ENDRES, P.A.; PISSARRA, T.C.T.; BORJES, M.J.; POLITANO, W. Quantificação das classes de erosão por tipo de uso do solo no município de Franca - SP. Engenharia Agrícola, Jaboticabal, v.26, n.1, p.200-207, 2006.

ENVIRONMENTAL SYSTEM RESEARCH INSTITUTE. Geoprocessing in ArcGIS 9.0. Redlands, California, USA: ESRI Inc., 2004.

FERREIRA, D.A.C.; DIAS, H.C.T. Situação atual da mata ciliar do Ribeirão São Bartolomeu em Viçosa, MG. Revista Árvore, Viçosa, v.28, n.4, p.617-623, 2004.

FLORENZANO, T.G. Imagens de Satélite para Estudos Ambientais. São Paulo: Oficina de Textos, 2002. 97p.

GASPARINO, D.; MALAVASI, U.C.; MALAVASI, M.M.; SOUZA, I. Quantificação do banco de sementes sob diferentes usos do solo em área de domínio ciliar. Revista Árvore, Manaus, v.30, n.1, p.1-9, 2006.

GOES, M.H.B. Bacia do rio Guandu: geomorfologia (mapa). In: Um Sistema de Informação Ambiental para a Bacia do Guandu RJ. Seropédica: UFRRJ, 2005.

GOES, M.H.B. Município de Seropédica: mapa de solos. Seropédica: UFRRJ, 2001.

Revista Árvore, Viçosa-MG, v.35, n.2, p.221-231, 2011
LIMA, W.P.; ZAKIA, M.J.B. Hidrologia de matas ciliares. In: RODRIGUES, R.R.; LEITÃO-FILHO, H.F. (Ed.). Matas Ciliares: conservação e recuperação. São Paulo: Edusp, Fapesp, $2^{a}$ ed, 2004. 320p.

MARTins, S.V. Recuperação de Matas Ciliares. Viçosa: Aprenda Fácil, 2001. 143p.

MIRANDA, E.E. (Coord.). Brasil em Relevo. Campinas: Embrapa Monitoramento por Satélite, 2005. Disponível em: <http://

www.relevobr.cnpm.embrapa.br>. Acesso: 25/10/2006.

NASCIMENTO, H.E.M.; LAURANCE, W.F. Efeitos de área e de borda sobre a estrutura florestal em fragmentos de floresta de terra-firme após 13-17 anos de isolamento. Acta Amazônica, Cidade, v.36, n.2, p.183-192, 2006.

NASCIMENTO, M.C.; SOARES, V.P.; RIBEIRO, C.A.A.S.; SILVA, E. Mapeamento dos fragmentos de vegetação florestal nativa da Bacia Hidrográfica do Rio Alegre, Espírito Santo, a partir de imagens do satélite IKONOS II. Revista Árvore, Cidade, v.30, n.3, p.389-398, 2006.

PANAVUE. PanaVue ImageAssembler Version 2.10. Québec, Canada: PanaVue Inc., 2002.

PIRES, J.S.R.; PIRES, A.M.Z.C.R.; SANTOS, J.E. Avaliação da integridade ecológica em bacias hidrográficas. In: SANTOS, J. E.; CAVALHEIRO, F.; PIRES, J. S. R.; HENKE-OLIVEIRA, C; RODRIGUES-PIRES, A. M. Z. C. Faces da Polissemia da Paisagem: ecologia, planejamento e percepção. São Carlos: RiMa, 2004, 409p.

RANTA, P.; BLOM, T.; NIEMELA, J.; JOENSUU, E.; SIITONEN, M. The fragmented Atlantic rain forest of Brazil: size, shape and distributions of forest fragments.

Biodiversity and Conservation, New York, v.7, p.385-403, 1998.

RODEWALD, A.D.; BAKERMANS, M.H. What is the appropriate paradigm for riparian forest conservation? Biological Conservation, Washington, v.128, p.193-200, 2006. 
SALVADOR, J.L.G. Comportamento de espécies florestais nativas em áreas de depleção de reservatórios. IPEF, Piracicaba, n.33, p.73-78, 1986.

SECRETARIA DE ESTADO DE MEIO AMBIENTE E DESENVOLVIMENTO SUSTENTÁVEL. Bacias Hidrográficas e Recursos Hídricos da Macrorregião Ambiental 2 - Bacia da Baía de Sepetiba. Rio de Janeiro: SEMADS, 2001, 79p
VELOSO, H.P.; GÓES-FILHO, L. Fitogeografia Brasileira. Salvador: Boletim Técnico - Projeto RadamBrasil, Série Vegetação, n.1, 1982. 85p.

YAMAJI, F.M. Análise Fractal de uma Floresta Ombrófila Mista Através de Imagens de Satélite. 2001. 120p. Dissertação (Mestrado em Engenharia Florestal) -

Universidade Federal do Paraná, Curitiba. 
